\title{
Comparison of three methods of tonometry in normal subjects: Goldmann applanation tonometer, non-contact airpuff tonometer, and Tono-Pen XL
}

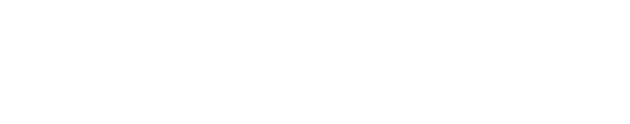

\author{
Ihsan Yilmaz \\ Cigdem Altan \\ Ebru Demet Aygit \\ Cengiz Alagoz \\ Okkes Baz \\ Sibel Ahmet \\ Semih Urvasizoglu \\ Dilek Yasa
}

Ahmet Demirok

Beyoglu Eye Training and Research Hospital, Istanbul, Turkey
Correspondence: Ihsan Yilmaz Bereketzade Cami Sokak No: 2 Beyoglu/lstanbul,Turkey Tel +90532 3455972 Fax +90212 2450948 Email ihsanyilmaz.dr@gmail.com
Objective: We aimed to compare intraocular pressure (IOP) measurements via three different tonometers: the Goldmann applanation tonometer (GAT), the Tono-Pen ${ }^{\circledR}$ XL (TPXL), and a non-contact airpuff tonometer (NCT).

Methods: This was a cross-sectional study of 200 eyes from 200 patients. Right eyes of all patients were included in this study. IOP was measured via GAT, NCT, and TPXL by three physicians. Each physician used one of the tonometers. Measurements via the three devices were compared.

Results: The mean IOP was $15.5 \pm 2.2 \mathrm{mmHg}$ (range 10-22) with the GAT, 16.1 \pm 3.0 (range 9-25) with the TPXL, and 16.1 \pm 2.8 (range 10-26) with the NCT. Bland-Altman analysis showed that the mean difference between measurements from the NCT and the GAT was $0.6 \pm 2.3 \mathrm{mmHg}$. The mean difference between the TPXL and GAT measurements was $0.7 \pm 2.5 \mathrm{mmHg}$. The mean difference between the NCT and TPXL measurements was $-0.02 \pm 3.0 \mathrm{mmHg}$. There was no significant difference between the groups according to a one-way analysis of variance (ANOVA) test. $P$-values were 0.998 for NCT-TPXL, 0.067 for NCT-GAT, and 0.059 for TPXL-GAT. Conclusion: The NCT and TPXL provide IOP measurements comparable to those of the gold standard GAT in normotensive eyes.

Keywords: tonometry, noncontact tonometry, Goldmann applanation tonometer, Tono-Pen

\section{Introduction}

Aqueous humor is secreted by the ciliary process to the posterior chamber and goes through the pupil to the anterior chamber (inflow). It then leaves the anterior chamber through the trabecular meshwork to the venous system (outflow). Normally, there is equilibrium between inflow and outflow that creates normal intraocular pressure (IOP). ${ }^{1,2}$ Any circumstances that affect the formation of aqueous humor or outflow of aqueous humor cause changes in IOP. Local and systemic disorders, medicines, and ocular surgeries affect IOP. Higher IOP levels are associated with ganglion cell and nerve fiber layer loss. The progression of damage eventually involves the optic nerve and irreversible visual loss. ${ }^{3}$

Glaucoma is the second leading cause of blindness worldwide. ${ }^{4}$ The only preventable risk factor for the development and progression of glaucoma is IOP. Correctly measuring IOP is very important in diagnosing glaucoma and conducting follow-ups. ${ }^{3}$ Medical, laser, or surgical treatments of glaucoma concentrate on lowering IOP. Earlier studies have shown that every $1 \mathrm{mmHg}$ drop in IOP decreases visual field 
damage by $10 \% .^{5}$ Therefore, precise measurements are very important.

Tonometry measures IOP with special devices. The ideal device must be easy to use, rapid, safe, and precise, irrespective of patient posture or age. Albrecht von Graefe invented the first tonometer in $1863 .{ }^{6}$ Today, we still have problems precisely measuring IOP in some conditions, such as in patients with corneal scar or corneal edema. The search for an ideal device continues.

Two different types of applanation tonometers exist. The first calculates IOP by measuring the flattened corneal area with constant force. The Maklakov tonometer, which was invented in 1885, is an example of this. ${ }^{6}$ The second applanation tonometer system calculates IOP by measuring the force needed to flatten a constant corneal area. A prototype of this is the Goldmann applanation tonometer (GAT; Haay-Streit AG, Koeniz, Switzerland), invented in the 1950s. Today, the GAT is most commonly used and is considered to be the gold standard device for measuring IOP. ${ }^{6}$ A GAT is mounted on a biomicroscope and a topical anesthesia-fluorescein dye is used. Because it flattens such a small area at the central cornea, measurements are not affected by scleral stiffness. However, the thickness of the central cornea may affect GAT readings.

Another applanation device is a non-contact tonometer (NCT; Nidek Co., Ltd., Aichi, Japan), also called an airpuff tonometer. An NCT uses air to flatten the cornea instead of touching it. ${ }^{7}$ The NCT has been available for about 40 years. $^{7}$

The Tono-Pen ${ }^{\circledR}$ XL (TPXL; Reichert Technologies, Depew, NY, USA) is a small and portable device that has been used since the 1980s. It is an applanation tonometer, and topical anesthesia is needed to measure the IOP.

In this study, we aimed to compare IOP measurements via the three different tonometers we routinely use in our clinic: GAT, TPXL (Reichert Inc, NY, USA), and Nidek NCT NT-530 (Nidek Co., Ltd., Aichi, Japan).

\section{Materials and methods}

This was a cross-sectional comparative study. A total of 200 eyes of 200 patients (108 female, 92 male) from our clinic in December 2013 were consecutively included. Only right eyes of all patients were included. Inclusion criteria were as follows: aged 18 years or more, no recent use of topical-systemic medicine, no use of contact lenses, no ocular surface disease, no significant degree of corneal astigmatism, no ocular pathology such as retinal disease or glaucoma, and no connective tissue disease. All patients in this study were volunteers and we complied with Helsinki ethical standards.

All types of IOP measurement were taken by three masked physicians via appropriately calibrated tonometers consecutively, with 10-minute intervals. All measurements were carried out at similar times, between 10 am and $11 \mathrm{am}$, to avoid early-morning changes in corneal thickness due to overnight edema. The NCT was used first. The eyes were then anesthetized using ALCAINE ${ }^{\circledR} 0.5 \%$ eye drops (Alcon Laboratories Inc., Fort Worth, TX, USA), and a second physician took measurements with the TPXL. Finally, ALCAINE was applied again and a fluorescein strip was applied to the inferior conjunctival fornix. A third physician took GAT measurements using the cobalt blue filter of a biomicroscope.

\section{Non-contact tonometer (NCT, airpuff)}

A Nidek NCT NT-530 automatically recorded three IOP readings. The device has a 5.7-inch color liquid crystal display, and the tilting function offers easy operation for a standing operator. The device has auto puff control (APC), which provides a quieter and softer puff of air for the patient's comfort. If the first puff is too strong, the device automatically uses a softer puff of air. This device takes about 10 seconds to measure the IOP of both eyes. The screen shows the results of three measurements, and their average for each eye is obtained by pressing a button three times. The average value was recorded for the study.

\section{Tono-Pen ${ }^{\circledR} \mathbf{X L}$}

The TPXL was calibrated daily. The device utilizes micro strain gauge technology and a $1.0 \mathrm{~mm}$ transducer tip. It uses batteries as a power source, and its measurement range is $5-80 \mathrm{mmHg}$, according to the user manual. After topical anesthesia is administered, the operator touches the covered tip of the TPXL to the cornea several times. Each touch to the anesthetized corneal surface is analyzed and stored by the device for statistical comparison. When four valid readings are obtained, the mean IOP and the standard deviation for those readings are shown on the liquid crystal display, which is situated on the side of the device. Measurements with standard deviations of five or less are accepted. Measuring both eyes takes about 30 seconds, including administration of the anesthetic and the patient's tolerance of the drops.

Finally, IOP was measured via a GAT, which takes about 3 minutes, including administration of the anesthetic 
and fluorescein. Three measurements were taken with the GAT and averaged.

We used SPSS version 20 (IBM, Armonk, NY, USA) software. The results were analyzed with Pearson's correlation, Bland-Altman plot, and one-way analysis of variance (ANOVA). The Scheffe method was used for post hoc comparison. A $P$-value of $<0.05$ was considered statistically significant.

\section{Results}

The mean age of patients was $47.7 \pm 12.6$ years (range 18-79). The mean IOP was $16.1 \pm 2.8 \mathrm{mmHg}$ (range 10-26) with the NCT, $16.1 \pm 3.0 \mathrm{mmHg}$ (range 9-25) with the TPXL, and $15.5 \pm 2.2 \mathrm{mmHg}$ (range 10-22) with the GAT. Figure 1 shows the IOP frequency of this study population when measured with the GAT.

A correlation analysis of NCT-GAT, TPXL-GAT, and NCT-TPXL measurements is shown in Figures 2, 3, and 4. An analysis indicates comparable performance between all instruments.

Results of the Bland-Altman plot are shown in Figures 5-7. The mean difference between the measurements in eyes by the different techniques was $0.6 \mathrm{mmHg}$ for NCT-GAT (Figure 5), $0.7 \mathrm{mmHg}$ for TPXL-GAT (Figure 6), and $-0.02 \mathrm{mmHg}$ for NCT-TPXL (Figure 7).

There was no significant difference between groups according to one-way ANOVA with Scheffe post hoc comparison test results. $P$-values were 0.998 for NCT-TPXL, 0.067 for NCT-GAT, and 0.059 for TPXL-GAT.

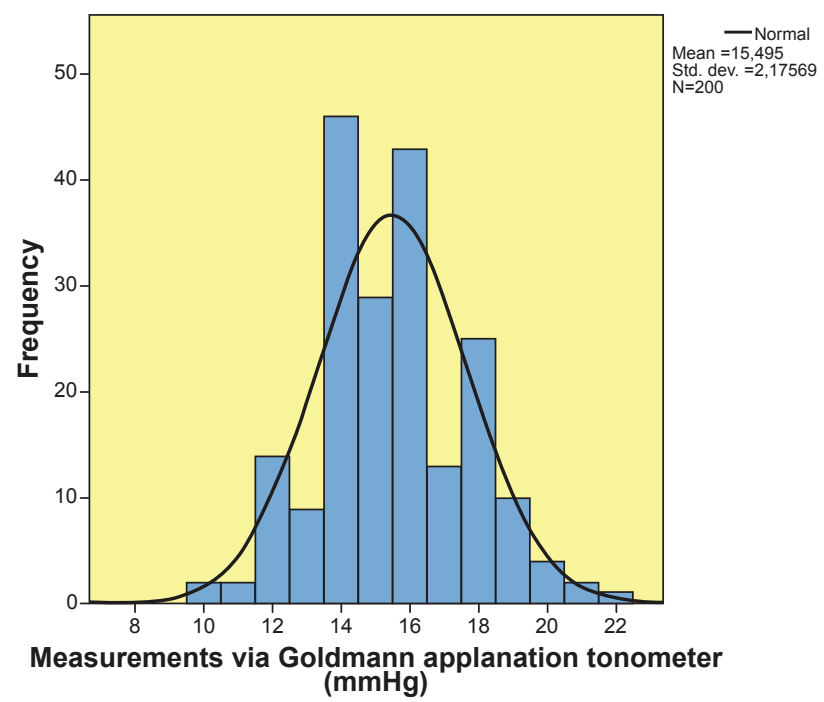

Figure I Frequency of intraocular pressure measurements $(\mathrm{mmHg})$ taken with the Goldmann applanation tonometer (GAT).

Note: GAT; Haay-Streit AG, Koeniz, Switzerland.

Abbreviation: Std. dev, standard deviation.

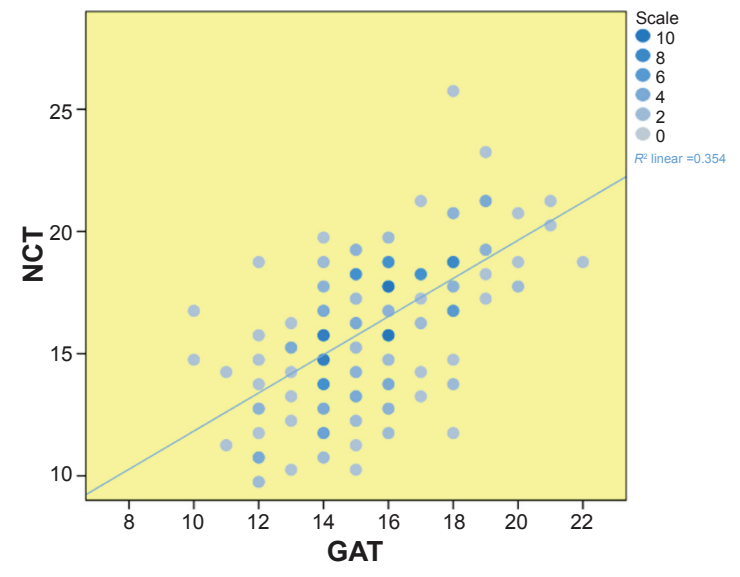

Figure 2 Correlation analysis of intraocular pressure measurements $(\mathrm{mmHg})$ taken with NCT and GAT.

Notes: The correlation is significant $\left(R^{2}=0.354, P<0.05\right)$. NCT; Nidek Co., Ltd. Aichi, Japan and GAT; Haay-Streit AG, Koeniz, Switzerland.

Abbreviations: GAT, Goldmann applanation tonometer; NCT, non-contract tonometer.

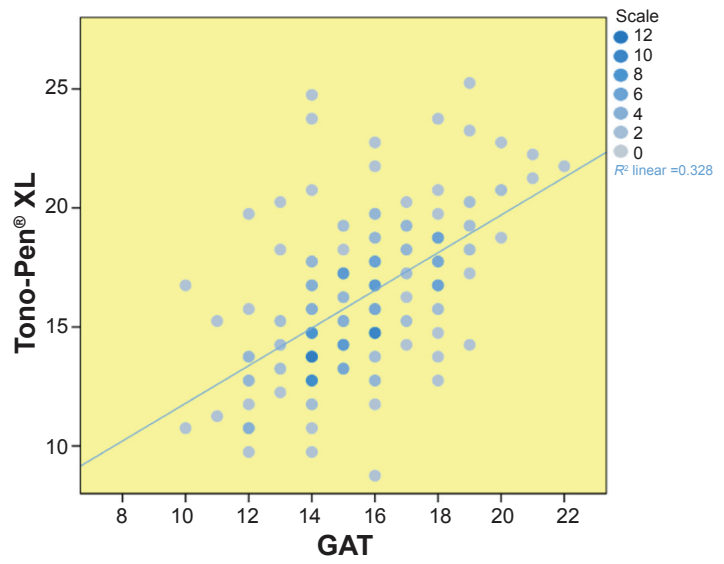

Figure 3 Correlation analysis of intraocular pressure measurements $(\mathrm{mmHg})$ taken with the Tono-Pen ${ }^{\circledR} \mathrm{XL}$ and the GAT.

Notes: The correlation is significant $\left(R^{2}=0.328, P<0.05\right)$. Tono-Pen ${ }^{\circledR} X L$; Reichert Technologies, Depew, NY, USA and GAT; Haay-Streit AG, Koeniz, Switzerland. Abbreviation: GAT, Goldmann applanation tonometer.

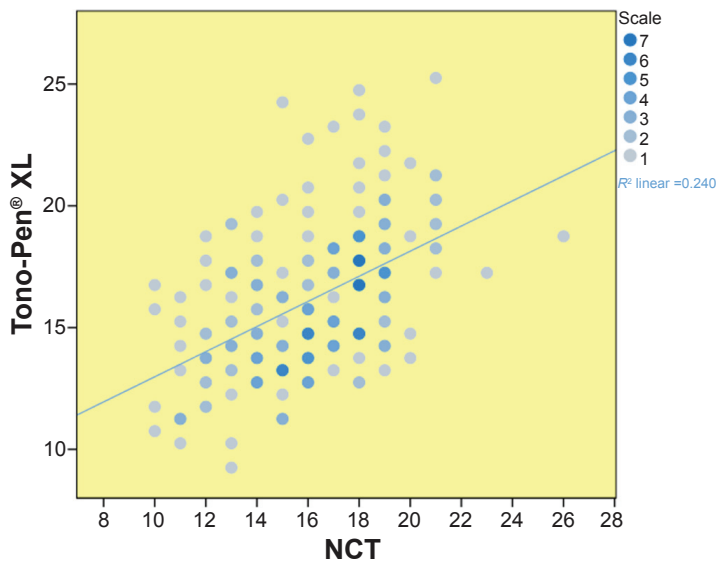

Figure 4 Correlation analysis of intraocular pressure measurements $(\mathrm{mmHg})$ taken with the Tono-Pen ${ }^{\circledR} \mathrm{XL}$ and an NCT.

Notes: The correlation is significant $\left(R^{2}=0.240, P<0.05\right)$. Tono-Pen ${ }^{\circledR} X L$; Reichert Technologies, Depew, NY, USA and NCT; Nidek Co., Ltd., Aichi, Japan. Abbreviation: NCT, non-contact tonometer. 


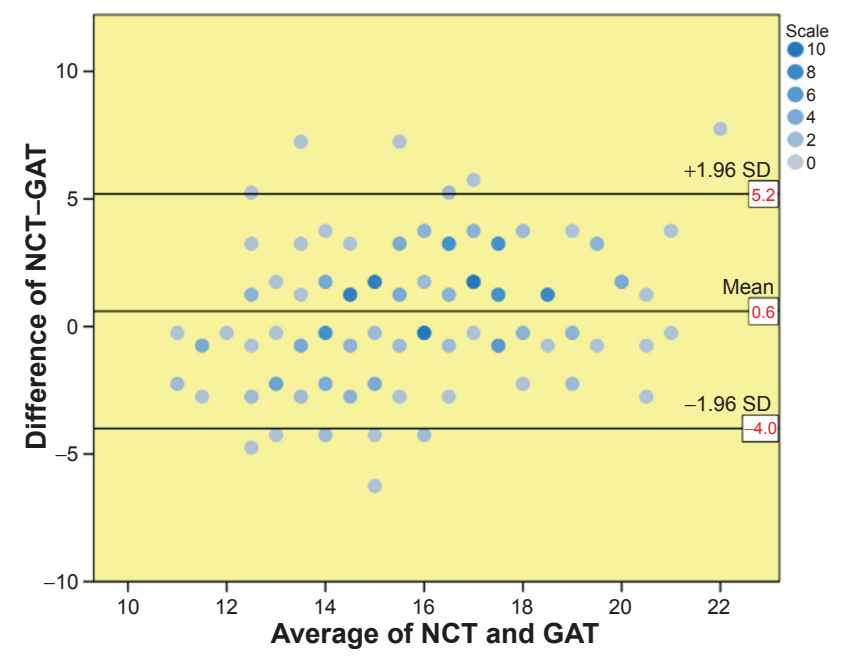

Figure 5 Bland-Altman test for correspondence between intraocular pressure measurements $(\mathrm{mmHg})$ taken with NCT and GAT.

Notes: The mean difference in intraocular pressure was $0.6 \mathrm{mmHg}$. NCT; Nidek Co., Ltd., Aichi, Japan and GAT; Haay-Streit AG, Koeniz, Switzerland.

Abbreviations: GAT, Goldmann applanation tonometer; NCT, non-contact tonometer; SD, standard deviation.

\section{Discussion}

GAT is still considered the gold standard and most commonly used method of tonometry. ${ }^{9}$ Nevertheless, the main disadvantages of the GAT include risk of contamination, the presence of common situations that lead to errors, and that it cannot be performed by assistant medical staff. It is commonly affected by corneal stiffness, thickness, scars, irregularities, and curvature. Steep corneas, thick corneas (except edema, which causes false-low readings), and against-the-rule astigmatism cause false-high

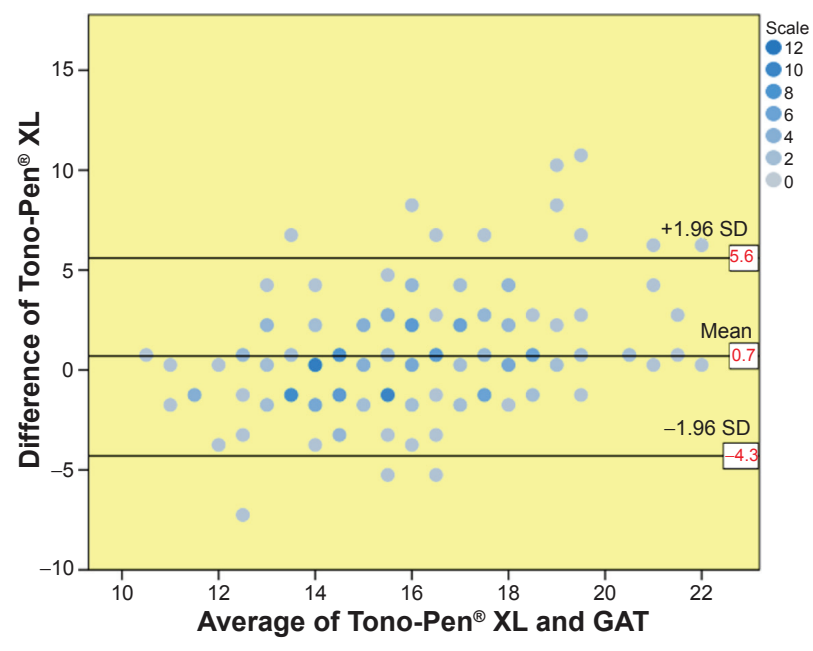

Figure 6 Bland-Altman test for correspondence between intraocular pressure measurements $(\mathrm{mmHg})$ taken with the Tono-Pen ${ }^{\circledR} \mathrm{XL}$ and the GAT.

Notes: The mean difference in intraocular pressure was $0.7 \mathrm{mmHg}$. Tono-Pen ${ }^{\circledR}$ XL; Reichert Technologies, Depew, NY, USA and GAT; Haay-Streit AG, Koeniz, Switzerland.

Abbreviations: GAT, Goldmann applanation tonometer; SD, standard deviation.

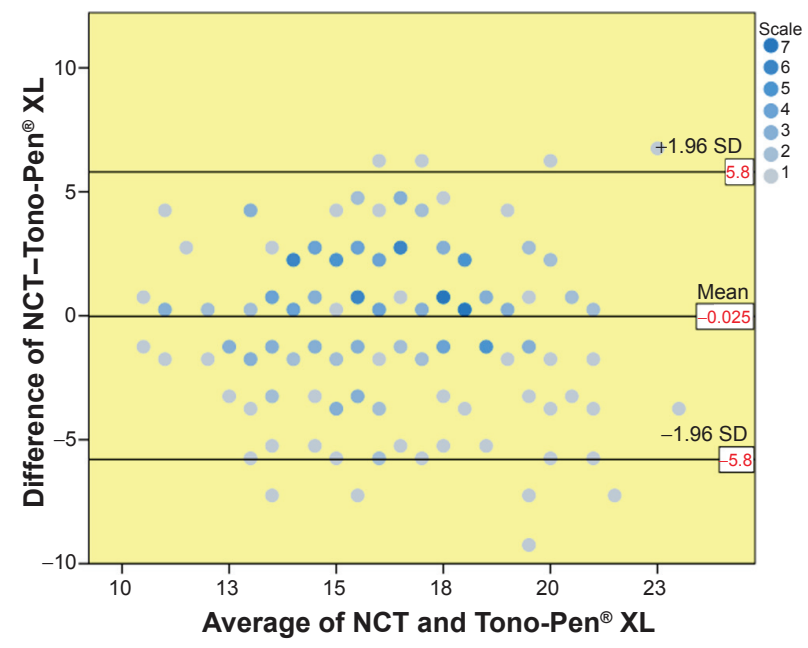

Figure 7 Bland-Altman test for correspondence between intraocular pressure measurements $(\mathrm{mmHg})$ taken with the NCT and Tono-Pen ${ }^{\circledR} \mathrm{XL}$.

Notes: The mean difference in intraocular pressure was $-0.025 \mathrm{mmHg}$. Tono-Pen ${ }^{\circledR}$ XL; Reichert Technologies, Depew, NY, USA and NCT; Nidek Co., Ltd., Aichi, Japan. Abbreviations: NCT, non-contact tonometer; SD, standard deviation.

readings. ${ }^{10}$ Thin corneas, with rule astigmatism, cause falselow readings. ${ }^{10}$ Insufficient fluorescein use causes false-low readings, and excessive fluorescein use causes false-high readings. The presence of corneal epithelial defects and previous corneal surgeries also complicate measurements. ${ }^{11}$ Finally, there is a contamination risk, so the tool tip must be cleaned after each use. ${ }^{12}$

Screenings with an NCT may be undertaken by nonmedical and unlicensed personnel under the supervision of a doctor. Because the NCT is a non-contact tool, there is no contamination risk. ${ }^{13,14}$ Furthermore, topical anesthetic drops or fluorescein dye are not necessary, which allows for rapid taking of measurements. The table-mounted NCT has some disadvantages (eg, the IOPs of small children and infants cannot be measured, and false-high readings are common if patients tighten their eyelids). The TPXL can easily be used in an office environment or in the operating room. ${ }^{8}$ After undergoing training, assistant health personnel can use the TPXL. ${ }^{15}$

The NCT and TPXL are easier and faster to use than the GAT, but suspicions about their results still exist. In this study, we found no significant differences between these three devices in normotensive patients. Other studies show similar results. ${ }^{16-22}$ Parker et a $1^{16}$ compared NCT and GAT and found results were concordant between the two devices. In another study, Tonnu et a ${ }^{17}$ compared NCT, TPXL, and GAT and reported that all three devices showed homologous results. ${ }^{17}$ However, other studies found contrasting results. ${ }^{23,24}$ Farhood $^{23}$ showed that NCT and GAT were not well correlated, and NCT measurements gave higher IOP 
results regardless of the patient's age or sex. In particular, when the GAT measurement exceeded $24 \mathrm{mmHg}$, the difference in readings between the two instruments increased. Farhood $^{23}$ reported that the lower the IOP as measured by GAT, the more reliable the corresponding NCT readings.

Other devices recently introduced to market are the Dynamic Contour Tonometer (DCT) and the Ocular Response Analyzer (ORA). Published studies have compared these new devices with GAT. ${ }^{25-28}$ Carbonaro et $\mathrm{al}^{25}$ compared GAT, DCT, and corneal-compensated IOP with the ORA and found similar reliability in all three devices.

\section{Conclusion}

In this study, we found that measurements taken with the Nidek NCT and the TPXL agree well with those via the GAT in normal subjects. Patients with extreme IOP levels were not included in this study, and some studies have shown that correlation errors between instruments occur within extreme IOPs beyond the normal range. ${ }^{23}$ However, our results showed that devices that are more practical and faster than the GAT may be used for screening normal subjects independently from central corneal thickness. Further studies that compare more devices in a larger case series are needed, as are studies investigating IOP measurement via different devices and comparing different patient groups (eg, different age groups, patients with previous corneal surgeries or corneal pathologies, or patients with glaucoma).

\section{Disclosure}

The authors declare there are no conflicts of interests regarding the publication of this article.

\section{References}

1. Chihara E. Assessment of true intraocular pressure: the gap between theory and practical data. Surv Ophthalmol. 2008;53(3):203-218.

2. Nebbioso M, Fazio S, Di Blasio D, Pescosolido N. Hypobaric hypoxia: effects on intraocular pressure and corneal thickness. Scientific World Journal. 2014;2014:585218.

3. Fernandes P, Díaz-Rey JA, Queirós A, Gonzalez-Meijome JM, Jorge J. Comparison of the ICare rebound tonometer with the Goldmann tonometer in a normal population. Ophthalmic Physiol Opt. 2005;25(5): 436-440.

4. Quigley HA. Number of people with glaucoma worldwide. $\mathrm{Br} J$ Ophthalmol. 1996;80(5):389-393.

5. Goldberg I. Relationship between intraocular pressure and preservation of visual field in glaucoma. Surv Ophthalmol. 2003;48 Suppl 1:S3-S7.

6. Stamper RL. A history of intraocular pressure and its measurement. Optom Vis Sci. 2011;88(1):E16-E28.

7. Forbes M, Pico G Jr, Grolman B. A noncontact applanation tonometer. Description and clinical evaluation. Arch Ophthalmol. 1974;91(2): 134-140.

8. Viestenz A, Lausen B, Jünemann AM, Mardin CY. [Comparison of precision of the TonoPenXL with the Goldmann and Draeger applanation tonometer in a sitting and recumbent position of the patients: a clinical study on 251 eyes]. Klin Monbl Augenheilkd. 2002;219(11):785-790. German.
9. AlMubrad TM, Ogbuehi KC. The effect of repeated applanation on subsequent IOP measurements. Clin Exp Optom. 2008;91(6):524-529.

10. Herr A, Remky A, Hirsch T, Rennings C, Plange N. Tonometry in corneal edema after cataract surgery: dynamic contour tonometry versus Goldmann applanation tonometry. Clin Ophthalmol. 2013;7: 815-819.

11. Hamed-Azzam S, Briscoe D, Tomkins O, Shehedeh-Mashor R, Garzozi H. Evaluation of intraocular pressure according to corneal thickness before and after excimer laser corneal ablation for myopia. Int Ophthalmol. 2013;33(4):349-354.

12. Regine F, Scuderi GL, Cesareo M, Ricci F, Cedrone C, Nucci C. Validity and limitations of the Nidek NT-4000 non-contact tonometer: a clinical study. Ophthalmic Physiol Opt. 2006;26(1):33-39.

13. Walia JS, Chronister CL. Possible iatrogenic transmission of Creutzfeldt-Jakob disease via tonometer tips: a review of the literature. Optometry. 2001;72(10):649-652.

14. Desai SP, Sivakumar S, Fryers PT. Evaluation of a disposable prism for applanation tonometry. Eye (Lond). 2001;15(Pt 3):279-282.

15. Theelen T, Meulendijks CF, Geurts DE, van Leeuwen A, Voet NB, Deutman AF. Impact factors on intraocular pressure measurements in healthy subjects. Br J Ophthalmol. 2004;88(12):1510-1511.

16. Parker VA, Herrtage J, Sarkies NJ. Clinical comparison of the Keeler Pulsair 3000 with Goldmann applanation tonometry. Br J Ophthalmol. 2001;85(11):1303-1304.

17. Tonnu PA, Ho T, Sharma K, White E, Bunce C, Garway-Heath D. A comparison of four methods of tonometry: method agreement and interobserver variability. Br J Ophthalmol. 2005;89(7):847-850.

18. Kao SF, Lichter PR, Bergstrom TJ, Rowe S, Musch DC. Clinical comparison of the Oculab Tono-Pen to the Goldmann applanation tonometer. Ophthalmology. 1987;94(12):1541-1544.

19. Frenkel RE, Hong YJ, Shin DH. Comparison of the Tono-Pen to the Goldmann applanation tonometer. Arch Ophthalmol. 1988;106(6): 750-753.

20. Bandyopadhyay M, Raychaudhuri A, Lahiri SK, Schwartz EC, Myatt M, Johnson GJ. Comparison of Goldmann applanation tonometry with the Tonopen for measuring intraocular pressure in a populationbased glaucoma survey in rural West Bengal. Ophthalmic Epidemiol. 2002;9(3):215-224.

21. Iester M, Mermoud A, Achache F, Roy S. New Tonopen XL: comparison with the Goldmann tonometer. Eye (Lond). 2001;15(Pt 1):52-58.

22. Ogbuehi KC. Assessment of the accuracy and reliability of the Topcon CT80 non-contact tonometer. Clin Exp Optom. 2006;89(5):310-314.

23. Farhood QK. Comparative evaluation of intraocular pressure with an air-puff tonometer versus a Goldmann applanation tonometer. Clin Ophthalmol. 2013;7:23-27.

24. Popovich KS, Shields MB. A comparison of intraocular pressure measurements with the XPERT noncontact tonometer and Goldmann applanation tonometry. J Glaucoma. 1997;6(1):44-46.

25. Carbonaro F, Andrew T, Mackey DA, Spector TD, Hammond CJ. Comparison of three methods of intraocular pressure measurement and their relation to central corneal thickness. Eye (Lond). 2010;24(7):1165-1170.

26. Sullivan-Mee M, Lewis SE, Pensyl D, Gerhardt G, Halverson KD, Qualls C. Factors influencing intermethod agreement between goldmann applanation, pascal dynamic contour, and ocular response analyzer tonometry. J Glaucoma. 2013;22(6):487-495.

27. Wang AS, Alencar LM, Weinreb RN, et al. Repeatability and reproducibility of Goldmann applanation, dynamic contour, and ocular response analyzer tonometry. J Glaucoma. 2013;22(2):127-132.

28. Salvetat ML, Zeppieri M, Tosoni C, Brusini P. Comparisons between Pascal dynamic contour tonometry, the TonoPen, and Goldmann applanation tonometry in patients with glaucoma. Acta Ophthalmol Scand. 2007;85(3):272-279. 


\section{Publish your work in this journal}

Clinical Ophthalmology is an international, peer-reviewed journal covering all subspecialties within ophthalmology. Key topics include: Optometry; Visual science; Pharmacology and drug therapy in eye diseases; Basic Sciences; Primary and Secondary eye care; Patient Safety and Quality of Care Improvements. This journal is indexed on

Submit your manuscript here: http://www.dovepress.com/clinical-ophthalmology-journal
PubMed Central and CAS, and is the official journal of The Society of Clinical Ophthalmology (SCO). The manuscript management system is completely online and includes a very quick and fair peer-review system, which is all easy to use. Visit http://www.dovepress.com/ testimonials.php to read real quotes from published authors. 